\title{
The role of reading, writing, using a computer, or watching television in the development of myopia
}

\author{
Maciej Czepita', Leszek Kuprjanowicz², Krzysztof Safranow ${ }^{3}$, Artur Mojsa ${ }^{2}$, Ewa Majdanik², \\ Maria Ustianowska ${ }^{2}$, Damian Czepita ${ }^{2}$ \\ ${ }^{1}$ Department of Pathology, Pomeranian Medical University, Szczecin, Poland \\ ${ }^{2}$ Department of Ophthalmology, Pomeranian Medical University, Szczecin, Poland \\ ${ }^{3}$ Department of Biochemistry and Medical Chemistry, Pomeranian Medical University, Szczecin, Poland
}

\begin{abstract}
INTRODUCTION. The purpose of our investigation was to evaluate in a Polish population the role of reading, writing, using a computer, or watching television in the development of myopia.

MATERIALS AND METHODS. In total 5601 students (2688 boys and 2913 girls, 6-18 years of age, mean $11.9+$ 3.2 years) were examined. The children examined were Polish students of elementary and secondary schools. In every student cycloplegia after $1 \%$ tropicamide was performed. Non-parametric tests were used due to the SE distribution being significantly different from normal distribution in Kolmogorow-Smirnov test. Spearman rank correlation coefficient (Rs) was used to evaluate the strength of correlation between these variables. General linear model was used for multivariate analysis. A P-value less than 0.05 was considered significant.

RESULTS. It has been established that with the increase in time spent on reading and writing, the spherical equivalent (SE) of the examined students decreases ( $\mathrm{Rs}=-0.16, \mathrm{p}<0.000001)$. It was observed that an increase in the time spent working on a computer correlates with the decrease of the $S E(R s=-0.11, p<0.000001)$. No relationship between watching television and the spherical equivalent of the examined schoolchildren was found ( $R s=+0.01$, $\mathrm{p}=0.31$ ).
\end{abstract}

CONCLUSIONS. Reading, writing, or using a computer may lead to the development of myopia. Watching television has no influence on the incidence of myopia.

KEY WORDS: myopia, refractive errors, prevalence

Ophthalmol J 2016; Vol. 1, No. 2, 53-57

\section{INTRODUCTION}

Myopia is a serious unsolved health problem in the contemporary world. It is believed that over $22 \%$ of the current world population has myopia. This translates to 1.5 billion people. In many East Asian countries the prevalence of myopia is rising sharply and has already reached $70-80 \%$ of the population. In Western countries $25-40 \%$ of peo- ple have myopia. In the United States the number of myopes has doubled in the past 30 years [1-3].

The incidence of myopia depends on genetic and environmental factors. An important environmental factor that influences the development of myopia is visual near work [4]. Many authors believe that reading, writing, and using a computer lead to a higher prevalence of myopia [5-16]. However, 


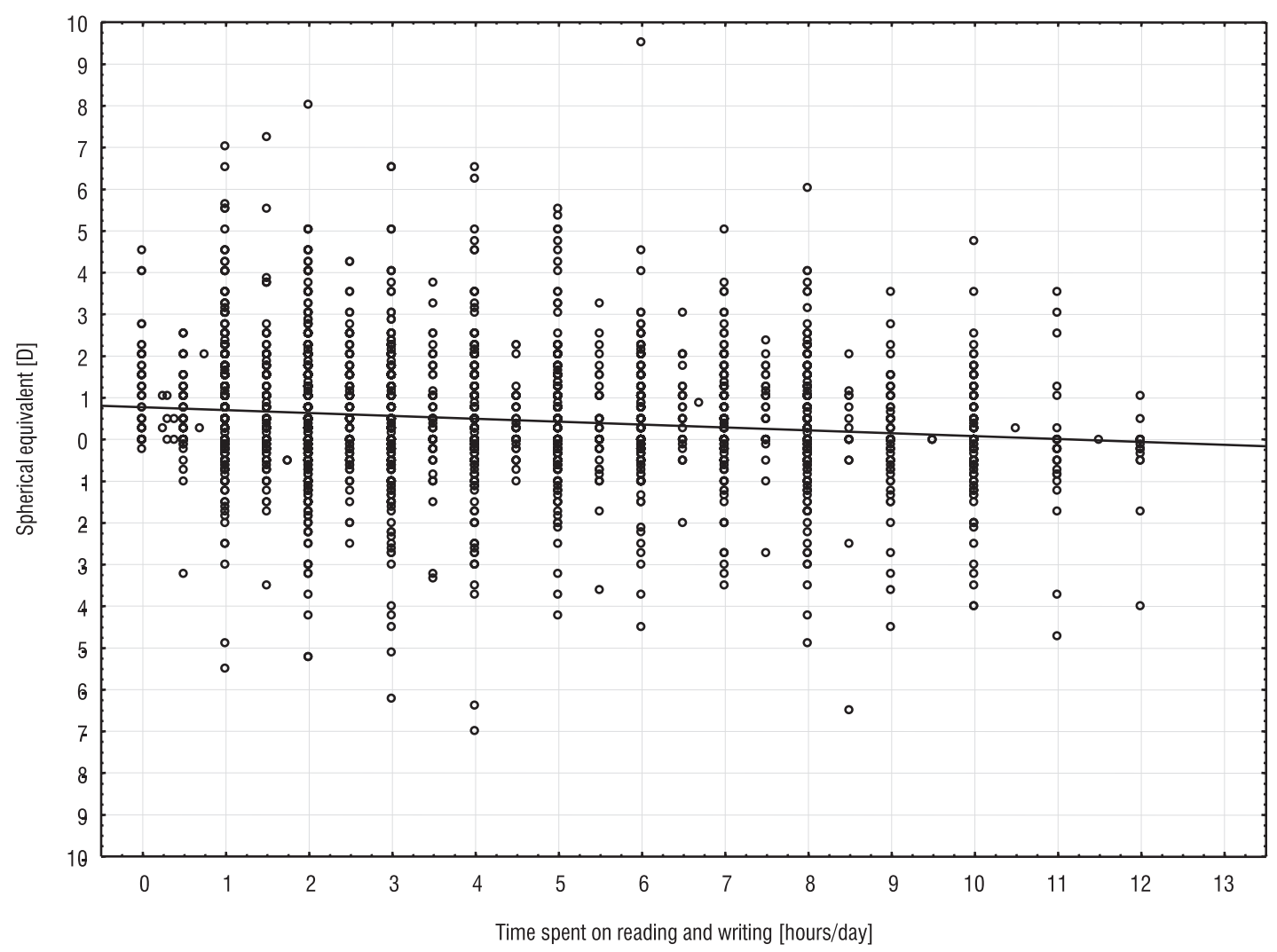

FIGURE 1. Mean spherical equivalent in relation to reading and writing

there have also been some publications that have not found such an association [17-23].

To the best of our knowledge only a few articles have been published so far that have studied the relationship between watching television and the development of myopia [6-10,12, 13, 16, 17]. In the majority of these studies no dependency between watching television and myopia has been described $[6,7,9,17]$.

Because of the differences in the obtained data we decided to evaluate, in a Polish population, the role of reading, writing, using a computer, or watching television in the development of myopia.

\section{MATERIALS AND METHODS}

A total of 5601 students (2688 boys and 2913 girls, $6-18$ years of age, mean $11.9+3.2$ years) were examined. The children examined (students of elementary and secondary schools) were Polish. In every student cycloplegia after $1 \%$ tropicamide was performed. The mean SE was calculated after examination of both eyes. The methods are described in detail in previous papers [6, 24].

The obtained results were entered into an EXCEL spreadsheet and analysed statistically using Statis- tica 10 software. Non-parametric tests were used due to the SE distribution being significantly different from normal distribution in Kolmogorow-Smirnov test. Spearman rank correlation coefficient (Rs) was used to evaluate the strength of correlation between these variables. A general linear model was used for multivariate analysis. A P-value less than 0.05 was considered significant.

\section{RESULTS}

It was established that with increase in the time spent reading and writing, the spherical equivalent of the examined students decreases ( $\mathrm{Rs}=-0.16$, $\mathrm{p}<0.000001$ ) (Fig. 1).

It was observed that the increase in time spent using a computer correlates with the decrease of SE (Rs $=-0.11, \mathrm{p}<0.000001)$ (Fig. 2).

No relationship between watching television and the spherical equivalent of the examined schoolchildren was found ( $\mathrm{R} s=+0.01, \mathrm{p}=0.31$ ) (Fig. 3).

Multivariate analysis has shown that independent factors associated with lower SE values are: older age $(\beta=-0.26, \mathrm{p}<0.000001)$, parents with myopia $(\beta=-0.15, \mathrm{p}<0.000001)$, being female $(\beta=-0.036, \mathrm{p}=0.006)$, longer time spent reading 


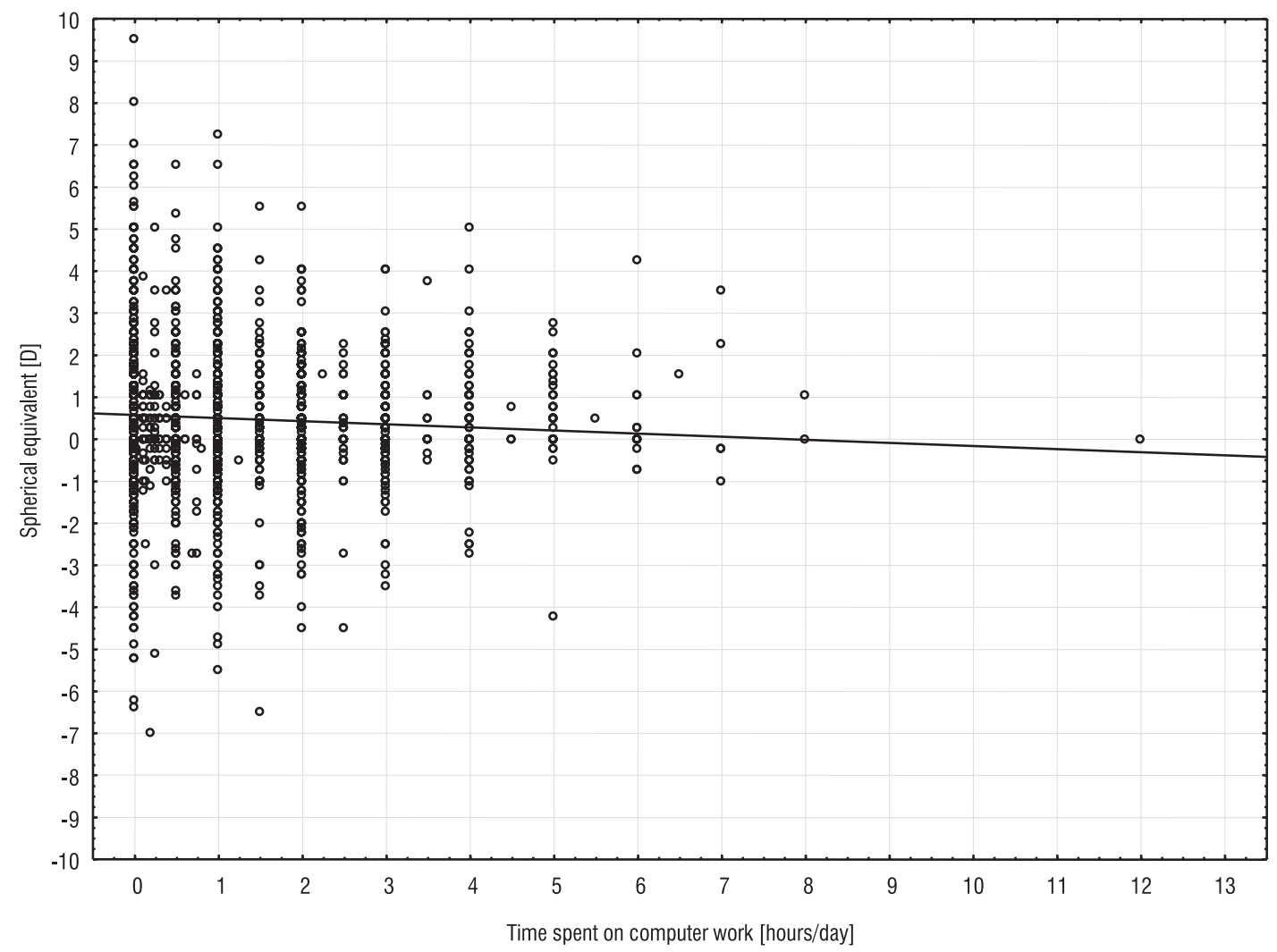

FIGURE 2. Mean spherical equivalent in relation to using a computer

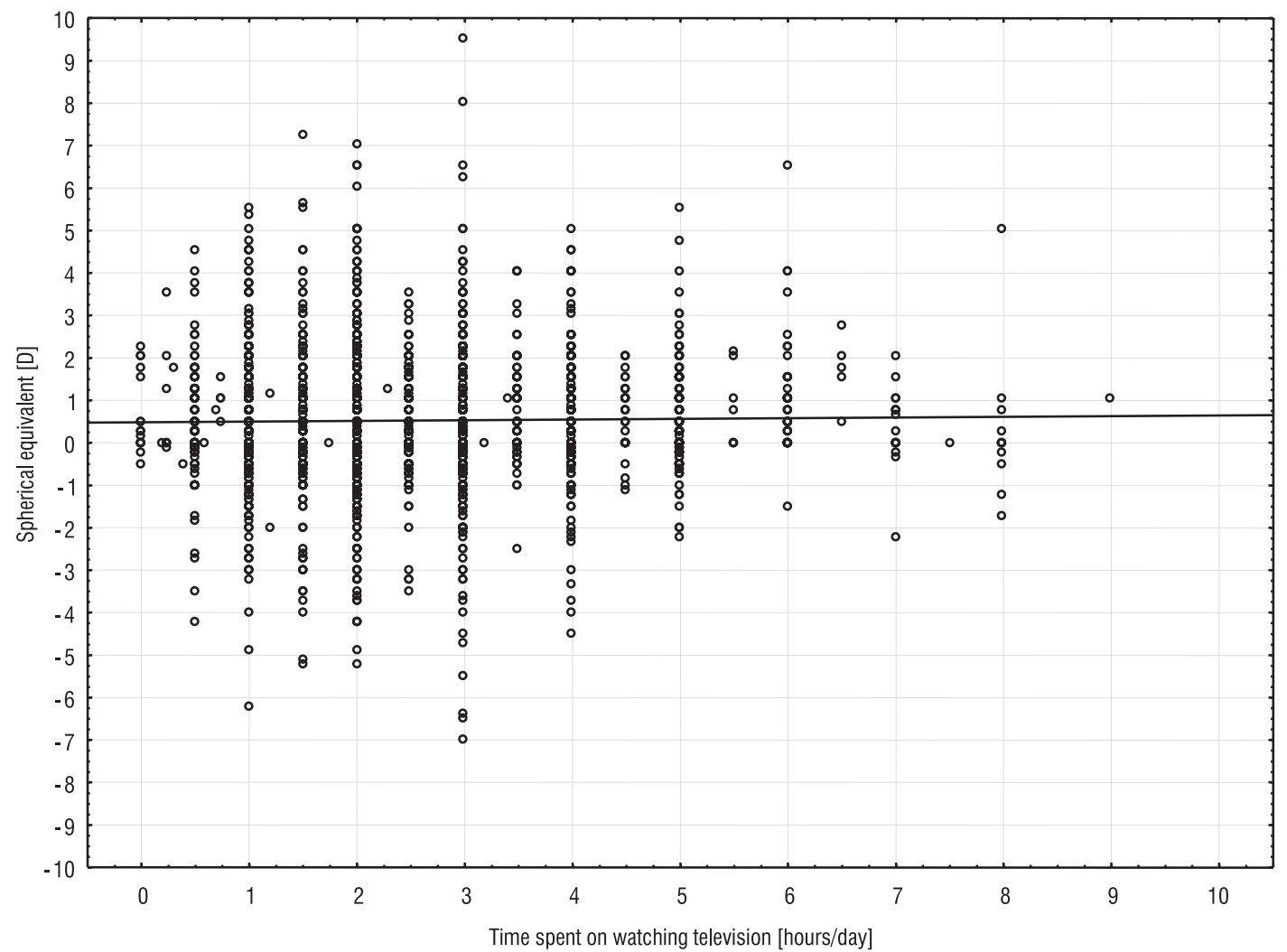

FIGURE 3. Mean spherical equivalent in relation to watching television 
Table 1. Dependency between reading, writing, using a computer, watching television, and myopia

\begin{tabular}{|c|c|c|c|c|}
\hline $\begin{array}{l}\text { First author, } \\
\text { year of publication }\end{array}$ & Country & $\begin{array}{c}\text { Dependency between } \\
\text { reading, writing, and } \\
\text { myopia }\end{array}$ & $\begin{array}{c}\text { Dependency between } \\
\text { using a computer and } \\
\text { myopia }\end{array}$ & $\begin{array}{c}\text { Dependency between } \\
\text { watching television and } \\
\text { myopia }\end{array}$ \\
\hline Nyman, 1988 & Sweden & & - & \\
\hline Wong, 1993 & Hong Kong & + & & \\
\hline Toppel, 1994 & Germany & & - & \\
\hline Cole, 1996 & Australia & & + & \\
\hline Mutti, 1996 & USA & & - & \\
\hline Rechichi, 1996 & Italy & & - & \\
\hline Kinge, 2000 & Norway & + & & \\
\hline Saw, 2001 & China & + & & \\
\hline Loman, 2002 & USA & - & & \\
\hline Mutti, 2002 & USA & + & & \\
\hline Khader, 2006 & Jordan & + & + & - \\
\hline Saw, 2006 & Singapore & - & & \\
\hline Jones, 2007 & USA & - & & - \\
\hline Konstantopoulos, 2008 & Greece & + & + & - \\
\hline Czepita, 2010 & Poland & + & + & - \\
\hline You, 2012 & China & + & + & + \\
\hline Pärssinen, 2014 & Finland & + & & + \\
\hline Li, 2015 & China & + & + & + \\
\hline Saxena, 2015 & India & + & + & + \\
\hline
\end{tabular}

and writing $(\beta=-0.044, \mathrm{p}=0.002)$, and less time watching television $(\beta=0.043, \mathrm{p}=0.0008)$.

\section{DISCUSSION}

In numerous papers a relationship has been described between reading, writing, or using a computer and the possibility of increased incidence of myopia (Tab. 1) [5-16]. However, as yet a mechanism for myopia development has not been found. It is assumed that the cues for the development of myopia are, among others, natural lag of accommodation and the associated retinal blur during near work [4].

In 2005 Buehren et al. [25] demonstrated that that the compression of the cornea by the eyelids during reading may be the cause of myopia. They explained this as the eyelids causing lower and higher order aberrations of the eye. These changes were observed to occur much more often in people with myopia than in emmetropia.

A year later Collins et al. [26] conducted similar research in which they demonstrated that reading, observing through a microscope, and working on a computer have different effects on corneal aberrations. The authors concluded that lid-induced corneal aberrations may lead to more frequent incidence of myopia.
Currently, most authors believe that watching television does not influence the prevalence of myopia (Tab. 1). [6, 7, 9, 17]. This is probably caused by the fact that when watching television our eyes do not accommodate and are aligned in the centre of the palpebral fissure.

Similar to the results of other researchers, we have concluded that reading, writing, or using a computer may lead to an increase in the development of myopia. We did not observe a dependency between watching television and the incidence of myopia.

The results obtained by us are credible because the examinations have been conducted under cycloplegia on a large population. Besides, the study was conducted on a racially homogenous group living in the same climatic conditions. This enables a precise evaluation of the role of reading, writing, using a computer, or watching television in the development of myopia.

\section{CONCLUSIONS}

Reading, writing or using a computer may lead to the development of myopia. Watching television has no influence on the incidence of myopia. 


\section{REFERENCES}

1. Holden B, Sankaridurg P, Smith E, Aller T, Jong M, He M. Myopia, an underrated global challenge to vision: where the current data takes us on myopia control. Eye 2014; 28: 142-146.

2. Wojciechowski R. Nature and nurture: the complex genetics of myopia and refractive error. Clin Genet 2011; 79: 301-320.

3. Zadnik K, Mutti DO. Incidence and distribution of refractive anomalies. In: Benjamin WJ, Borish IM (eds.) Borish's clinical refraction. Butterworth Heinemann, Elsevier, St Louis 2006: 35-55.

4. Goss DA. Development of ametropias. Borish's clinical refraction. Butterworth Heinemann, Elsevier, St Louis 2006: 56-92.

5. Cole BL, Maddocks JD, Sharpe K. Effect of VDUs on the eyes: report of a 6-year epidemiological study. Optom Vis Sci 1996; 73: 512-528.

6. Czepita D, Mojsa A, Ustianowska M, Czepita M, Lachowicz E. Reading, writing, working on a computer or watching television, and myopia. Klin Oczna 2010; 112: 293-295.

7. Khader YS, Batayaha WQ, Abdul-Aziz SMI, Al-Shiekh-Khalil MI. Prevalence and risk indicators of myopia among schoolchildren in Amman, Jordan. East Mediterr Health 2006; 12: 434-439.

8. Kinge B, Midelfart A, Jacobsen G, Rystad J. The influence of near-work on development of myopia among university students. A three-year longitudinal study among engineering students in Norway. Acta Ophthalmol Scand 2000; 78: 26-29.

9. Konstantopoulos A, Yadegarfar G, Elgohary M. Near work, education, family history, and myopia in Greek conscripts. Eye 2008; 22: 542-546.

10. Li SM, Li SY, Kang MT et al. Near work related parameters and myopia in Chinese children: the Anyang Childhood Eye Study. PloS One 2015; DOI:10.1371/journal.pone.0134514.

11. Mutti DO, Mitchell GL, Moeschberger ML, Jones LA, Zadnik K. Parental myopia, near work, school achievement, and children's refractive error. Invest Ophthalmol Vis Sci 2002; 43: 3633-3640.

12. Pärssinen 0 , Kauppinen $M$, Viljanen $A$. The progression of myopia from its onset at age 8-12 to adulthood and the influence of heredity and external factors on myopic progression. A 23-year follow-up study. Acta Ophthalmol 2014; 92: 730-739.

13. Saxena R, Vashist P, Tandon R, Pandey RM, Bhardawaj A, Menon $\mathrm{V}$, Mani K: Prevalence of myopia and its risk factors in urbal school children in Delhi: the North India Myopia Study (NIM Study). PloS One 2015; DOI:10.1371/journal.pone.0117349.

14. Saw SM, Hong RZ, Zhang MZ et al. Near-work activity and myopia in rural and urban schoolchildren in China. J Pediatr Ophthalmol Strabismus 2001; 38: 149-155.

15. Wong $\mathrm{L}$, Coggon $\mathrm{D}$, Cruddas $\mathrm{M}$, Hwang $\mathrm{CH}$. Education, reading, and familial tendency as risk factors for myopia in Hong Kong fishermen. J Epidemiol Community Health 1993; 47: 50-53.

16. You Q, Wu LJ, Duan JL et al. Factors associated with myopia in school children in China: the Beijing Childhood Eye Study. PloS One 2012. DOI:10.1371/journal.pone.0052668.

17. Jones LA, Sinnott LT, Mutti DO, Mitchell GL, Moeschberger ML, Zadnik K. Parental history of myopia, sports and outdoor activities, and future myopia. Invest Ophthalmol Vis Sci 2007; 48: 3524-3532.

18. Loman J, Quinn GE, Kamoun L et al. Darkness and near work. Myopia and its progression in third-year law students. Ophthalmology 2002; 109: 1032-1038.

19. Nyman KG. Occupational near-work myopia. Acta Ophthalmol Suppl 1988; 185: 167-171.

20. Rechichi C, Scullica L. Trends regarding myopia in video terminal operators. Acta Ophthalmol Scand 1996; 74: 493-496.

21. Saw SM, Shankar A, Tan SB et al. A cohort study of incident myopia in Singaporen children. Invest Ophthalmol Vis Sci 2006; 47: 1839-1844.

22. Toppel L, Neuber M. Evaluation of refractive correction in persons working at video display terminals. Ophthalmologe 1994; 91: 103-106 (in German with English abstract).

23. Mutti D0, Zadnik K. Is computer use a risk factor for myopia? J Am Optom Assoc 1996; 67: 521-530.

24. Czepita D, Żejmo M, Mojsa A. Prevalence of myopia and hyperopia in a population of Polish schoolchildren. Ophthal Physiol Opt 2007; 27: 60-65.

25. Buehren T, Collins MJ, Carney LG. Near work-induced wavefront aberrations in myopia. Vision Res 2005; 45: 1297-1312.

26. Collins MJ, Buehren T, Bece A, Voetz SC. Corneal optics after reading, microscopy and computer work. Acta Ophthalmol Scand 2006; 84: 216-224. 
